\title{
IF IT AIN'T BROKE, IMPROVE IT: THOUGHTS ON ENGAGING EDUCATION FOR US ALL
}

Steven W. Gilbert

President

The TLT Group

One Columbia Avenue

Takoma Park, MD 20912

Phone: (301) 270-8310

gilbert@,tltgroup.org

\begin{abstract}
One of the continuing challenges of education is enabling those who strive to improve teaching, learning, and research to take advantage of the too-rapidly-changing new environment created by telecommunications and information technologies. To do so, educational professionals should engage in lifelong professional development and use new hybrid technologies to help build community and support collaboration. This paper explores the issues of technology and professional development from the frame of reference of my work with hundreds of colleges that have benefited from the Teaching, Learning, and Technology Group (TLT Group), an organization whose mission is to motivate and enable institutions and individuals to improve teaching and learning with technology, while helping them cope with change. This article discusses challenges that higher education faces: creating visions worth working toward; developing strategies and tools for achieving intermediate goals; and the importance of breaking taboos along the way.
\end{abstract}

\section{KEY WORDS}

TLT Group, Information technology, Professional development, Information literacy, Low-threshold Applications and Activities (LTAs)

\section{INTRODUCTION}

The most important challenge facing higher education today is not technological, not political, not managerial, and not financial, although those are all important factors. The biggest, most important challenge is educational.

Higher education is richer with options for improving teaching and learning than ever before, and these options change more rapidly than ever before. The variety and power of new kinds of information resources increase just as quickly. New telecommunications and information technologies contribute both to the necessity and the means for keeping up with these changes. Enabling millions of citizens, including professional educators, to think, decide, and act differently is a task for which educators are still the best prepared and most needed.

However, our continuing challenge is to enable faculty, students, and other professionals who also strive to improve teaching, learning, and research to take fullest advantage of this new environment and to avoid 
new pitfalls. To do so, lifelong professional development programs can and should take advantage of new hybrids of technologies (e.g., synchronous and asynchronous) and educational approaches that can build community and support collaboration. These programs can and should enable participants to gain new insights, skills, and experience as they learn how to develop and apply similar hybrids themselves in their own work as teachers, researchers, librarians, instructional designers, tech-support professionals, and administrators. Finally, these programs can and should support and constructively exploit the distinct abilities of these same professionals to contribute to their own professional development and that of their colleagues. Lifelong learning isn't only for "them." It is for all of us; and lifelong professional development is an important part of it, for now and for the foreseeable future.

In the sections that follow, we will explore these issues from the frame of reference of our work with hundreds of colleges who have worked with us and the Teaching and Learning and Technology Group (www.tltgroup.org). We will explore the challenges higher education faces; visions and goals worth working toward; principles, strategies, and tools for working toward these worthwhile ends; and some final thoughts on breaking taboos. In the end, we hope you too will join in the call for engaging education for us all.

\section{CHALLENGES}

\section{A. Not Broken}

Our colleges are not broken. No one technology, theory, fad, or person can fix education; there is no solution. We cannot repair it in the sense of making some kind of significant change and expecting to say, "OK, all better!"

Our faculty members and other academic professionals are not failures. More people are getting better educated now than ever before in the United States. More people from other countries want to enter our education system than our citizens want out. Of course, we are facing some difficult challenges and some unavoidable changes.

What we can do is make some improvements while respecting what has already been accomplished, honoring those who are continuing to do well, and supporting the continuation of efforts to improve teaching and learning in an environment that is richer with options that are changing more rapidly than ever before but in an environment that is not alien or incomprehensible. All of us involved in higher education need to use the wisdom, knowledge, and skills that we have as educators to design and implement educational responses to these new educational challenges.

Education is not broken, and it will never be perfect. The best educators are never satisfied with the present. They are always striving to improve teaching, learning, and research. Often, they succeed.

\section{B. Expectations Rise Faster Than Resources: Need for Collaboration Grows}

Most gains in efficiency using information technology for academic purposes are more than offset by rising expectations that even more should be accomplished. Consequently, most of those involved are more often disappointed than proud of what they are doing. How can we avoid the resulting stress and frustration? Collaboration-especially in support of professional development that enables faculty members and other academic professionals to help each other keep learning to take better advantage of new resources - may provide part of the answer. But only if we can break some old taboos along the way. 
Ten years ago, many of us saw that we needed new kinds of collaboration across old departmental boundaries to take full advantage of new options for improving teaching and learning with technology within a college or university. Today that need is even greater.

The growing power and accessibility of Student Information Systems, institutional web-based portals, web-based Course Management Platforms, electronic portfolios, online course registration, e-commerce, and other new technology applications increase the potential for improving teaching and learning in colleges through more effective linkages between academic and administrative systems. The traditional separation of administrative-operational computing from academic computing has become unworkable.

As more people within an institution depend on more complex interlinked systems, the reliability and ease of use of those systems becomes more important. But those same systems continue to become more complex and to change rapidly. Consequently, the professional support staff become more important for implementing changes, fixing more frequent inevitable breakdowns, and (re)training users-just when most budgets for support staff are decreasing.

The Teaching, Learning, and Technology Roundtable (TLTR) program was launched early in 1995 in response to those needs. Since then, higher education has made great progress and learned much; however, the challenges have grown at least as fast as the opportunities. We have many attractive new tools and new options, but the need for collaboration has deepened and widened: Colleges and universities now need alliances that cross even more internal boundaries and engage the participants more actively in developing programs that require better communication, more cost-effective collaboration, and more significant compromises.

During the first years of launching hundreds of TLTRs, we frequently asked a pair of Fundamental Questions. We were able to ask these questions of diverse groups within hundreds of different kinds of colleges and universities:

- What do you most want to gain? For yourself? For your colleagues? For your institution?

- What do you most cherish and want not to lose? For yourself? For your colleagues? For your institution?

The one dominant theme in all the answers, among all the discussions, was, "We don't want to lose our opportunities to connect meaningfully and deeply with students."

The good news: Some offices and departments in many colleges have learned to work together better; we have more powerful, ubiquitous technology and better tools to support these processes; and those tools are still improving.

The bad news: Many more interdepartmental and interoffice walls must be breached; people behind those walls have little experience doing so and are naturally loath to change how they work to include more collaboration; the underlying technology has become more fragile and unreliable (temporarily?); and expectations continue to grow faster than resources. 


\section{The Big Changes for Faculty and Those Who Support Teaching and Learning}

Long ago (pre-1980): Options for teaching and learning were very few.

Most faculty could find and use the limited instructional resources available from a few well-known sources that didn't change very rapidly, in a few well-known formats and media (mostly books, teacher's guides, articles, lab equipment). The main instructional challenges for faculty members were keeping up to date in their slowly changing academic fields, organizing the content for courses, and mastering the very limited options for classroom activities and homework assignments.

Not so long ago (1980s): Options for teaching and learning were still very few.

Most faculty could still find and use the limited instructional resources that were still usually available from a few well-known sources in a few well-known formats and media; but the amount of useful, relevant information changed (grew) much more rapidly. The main instructional challenges for faculty members were keeping up to date in their more rapidly changing academic fields, organizing the content for courses, and mastering the very limited options for classroom activities and homework assignmentsand beginning to use computers and telecommunications in their own research and office work and for instruction.

More recently (mid-1990s to present): Options for teaching and learning are many and increasing rapidly. Most people, including faculty, academic support professionals, and students, do not know how to find with certainty the best instructional resources available and useful for their courses. In most academic disciplines, the content continues to grow quickly, but the instructional options are now available from a changing variety of not-so-well-known sources in formats that are still evolving.

\section{Other Daunting Observations?}

History suggests that most faculty members are unable to take advantage of new instructional options on their own. Most faculty are unprepared and already too busy to take advantage on their own of new technology-based options for improving teaching, learning, and research.

Higher education has traditionally rewarded independent achievement and discouraged or penalized collaborative work. Most faculty and other academic professionals have little experience collaborating on instructional tasks within their own departments or offices, and even less experience doing so with colleagues from other departments, offices, or institutions.

External pressures are growing for more faculty, students, librarians, and faculty development professionals to make more frequent and effective use of information technology because

- Most students expect it;

- Many technology applications have become essential for work in certain areas of some academic disciplines;

- The installed technology and support-service infrastructure already appears to support many instructional and other useful applications - If you've got it, use it;

- Widely available, publicized, and (mostly) reliably accessible communications tools, information organization tools, and information distribution tools (e.g., email, Google, databases) are very attractive; and

- Some academic leaders believe that they must compete for students who can only or most 
conveniently participate via distance technology.

Demand is still increasing for the services of colleges, universities, and libraries. Budgets are being cut as revenues from a variety of sources shrink. Old responsibilities continue-mostly undiminished. In spite of the addition of new responsibilities, fulfilling their old responsibilities continues to be close to a full-time job for most faculty members, librarians, academic support staff, and technology support staff.

\section{WHY BOTHER: VISIONS AND GOALS WORTH WORKING TOWARD}

In the face of all these difficulties, why do so many continue to work so hard to improve teaching and learning with technology? In part, we do so because we have passed the point of no return for use of information technology in higher education. There is no realistic path forward that includes removing the technology infrastructure already in place: computers, networks, classroom projection equipment, software, email, and the web, to name a few.

But I believe that the stronger reason is that so many faculty members and other academic professionals really want to improve teaching and learning, and research, and build community among teachers and learners. And information technology seems to provide new opportunities for making changes, for improving some of the activities most important to faculty, students, and others committed to higher education. For a summary of many different answers to this Why bother? question, see http://www.tltgroup.org/WhyBother.htm

Here are my own visions worth working toward, based on decades of work with hundreds of educational institutions and thousands of educators.

\section{A. Engagement in Education}

Be skeptical when you hear someone describe education as a "delivery system."

Why is it so hard to resist thinking of education as a delivery system for information? Why, especially, in tough financial times? And, why, especially, when new information technology applications appear to convert live presentations ever more completely into digital formats?

Some kinds of very valuable teaching and learning can be handled effectively by focusing solely on the task of packaging, organizing, and transferring information from one person to many others - using education as a delivery system. Some education can benefit from as much uniformity and standardization as possible with respect to everyone involved. If those who advocate and excel at this kind of education were content to use it only where it is most valuable (e.g., training in very specific skills or facts), that would be dandy. But some decision makers, who seem unaware of the great range of teaching and learning practices and purposes, embrace the delivery system model too quickly and want to apply it too widely - to the exclusion of all others.

Thinking of education as only an information delivery system can make us feel that we can understand, control and reduce the costs of something that is really much more multidimensional and complex. Modern information technology (and other technologies before it, such as books) can indeed be used to achieve some significant economies of scale in delivering information. But much of education is not 
simply a delivery system.

I leave the delivery-system model for others to advance and support. I respect their efforts so long as they exercise good judgment in limiting the scope of their approach to situations where it is appropriate and if their work is done efficiently, cost-effectively, and caringly. Meanwhile, I will focus on the kinds of education that foster more opportunities for faculty members to connect meaningfully and deeply with students and with others in the community, broadly defined-especially those kinds of education that offer the connectedness that Edward Hallowell [1] and others have so eloquently described:

- Familial connectedness

- Historical connectedness

- Social connectedness

- Institutional-Organizational connectedness

- Connectedness to information and ideas

- Religious-Transcendent connectedness

Fortunately, new tools and media are making it possible to provide more opportunities for communication, coordination, collaboration, and engagement within college courses and among those who support teaching and learning.

\section{B. Building Community (Collaboration, Communication)}

"Community" is a term that is especially important, and especially problematic, in education today. We can use computers, the internet, and other means of telecommunications to link more kinds of people, in more kinds of ways, than ever before. But these distributed groups are often composed of people who are distant from one another at least some of the time, different from one another, and somewhat unfamiliar to one another. The preceding sentence is not a bad description of a traditional campus, with its many departments and offices. But it's an even better description of what online interaction makes possible: communities of professionals and learners whose specialties are diverse, whose potential is great, whose engagement with one another is only part-time but extended over years, whose face-to-face interaction is occasional, and whose ability to make connections and decisions with each other has been limited by these conditions.

One of the most important steps in building community online and on campus is to define community more clearly and identify the elements that matter most to those involved. The TLT Group has begun a symposium, online and face-to-face, in which we will help each other clarify what we mean by community and identify principles, tools, and resources that help each of us move closer to articulating and achieving those elements of community most important to us. We will consider different kinds of communities as well as the strategies and tactics, hopes, and dangers of creating functioning groups that do much of their work and interaction online.

We are finding it both provocative and helpful to collect stories about incidents where the boundaries between professional and personal interactions are stretched or torn. Recognizing how those boundaries differ for many of us is often a good basis for sharpening our understanding of how differently we identify and experience various dimensions of community.

We do not expect ever to reach unanimity about the meaning and appropriate use of the term 
"community." Rather, we find it useful to articulate the important characteristics and dimensions of affiliation that are possible and desirable for different kinds of groups under different circumstances. We hope to identify or develop ways to support efforts to achieve and sustain those community-like affiliations, especially using new options made possible by new information technologies, information resources, and telecommunications media.

Here, I offer questions for articulating important elements of community:

- Where are the comfortable boundaries for you between professional and personal interactions?

$\circ$ Within a course?

- Within your office or department?

○ Within your institution?

- Within your academic field or profession?

- Which other elements of community and collaboration are most important to you

(i.e., in addition to person-professional boundary; e.g., duration of mutual commitment)?

$\circ$ Within a course?

$\circ \quad$ Within your office or department?

- Within your institution?

- Within your academic field or profession?

- Which applications of information technology and which approaches to teaching, learning, and research support these important elements?

Collaborative change requires collaborative support. For finding, developing, adapting, using, evaluating, modifying, and sharing technology-based instructional resources, administrative and operational resources, technological improvements are only partial solutions. Technological improvements can help, but unsupported, they are not solutions; they are not reliable or easy to use; they are not Low-Threshold Applications (LTAs). New tools enable new forms of collaboration, new forms of support services! Such tools, when supported, can help us avoid the need to use the strategy suggested by Moss [2]: "If working 24 hours a day isn't enough, you have to work nights."

\section{Lifelong Professional Development: Taking Advantage of Underutilized Unique Resources}

Too many faculty members swallow the delivery model of education whole and, consequently, ask plaintively, "If I put my course on the web using Blackboard, WebCT, Angel, or any other course platform, will the college need me next year?" and, "If I put my lecture notes and readings on the web, will any students come to my classes?" But these questions evaporate when faculty and those who help them concentrate on developing and using the full range of their capabilities to make courses more deeply meaningful and engaging - especially by taking the fullest advantage of face-to-face and other kinds of synchronous interactions.

[NOTE: Obviously, organizing course subject matter and delivering information continue to be important functions, but they should not be treated as if they were the only functions! What I describe below underemphasizes these functions only because they are overemphasized and dealt with more fully by so many others. Any continuing, effective professional development program must include both delivery and engagement elements.] 
Professional development can reassure academics of the importance of their changing roles by enabling them to recognize how they have already been doing more than delivering information to students. Professional development can help them understand and use new applications of information technology to support their long underlying educational goals, to make their teaching and their students' learning valuable in many ways beyond simple exchange of information. Professional development can offer new ways of doing so, especially based on newly available tools and practices.

To take advantage of some of these new options, faculty and other academic professionals must overcome a new challenge: keeping up with three fields instead of one. In addition to keeping up with the continuing and accelerating growth of knowledge in most academic disciplines and related professions, these individuals are now expected to keep up with two more kinds of information explosion: instructional resources and information resources. Older academics had to work hard to learn to keep up with the accelerating pace of change in their own disciplines or fields of expertise. Their younger colleagues may specialize more narrowly to help cope with this acceleration, but all find it a continuing challenge.

And that challenge has not abated as they face new learning responsibilities often imposed by themselves more strongly than by anyone else. They feel the need to try to keep up with and take advantage of technology-based instructional options that appear to be relevant to their own instructional responsibilities.

While few of them think of information literacy for themselves, they do recognize the rapidly increasing complexity of the information resource environment in which they live. They often suspect resources exist that would meet their own needs even better that are lurking somewhere beyond their comprehension or reach. Librarians can help, but they are subject to the same increases in workload and challenges, and most of them have little extra time to provide additional collaborative support efforts of this sort. And many faculty members are unaccustomed to seeking or accepting help from librarians or from other academic support professionals.

The wisdom, knowledge, and skills we have collectively as educators meet with new technological tools and resources. Learning how to apply these eclectic combinations to the teaching and learning of undergraduates, continuing education, and graduate students, also benefits our own professional development. Lifelong professional development is an important part of lifelong learning.

Just as the need for more lifelong professional development is increasing, budgets for support service staff and related expenses are shrinking. Faculty, especially, have less time, less travel money, and are becoming less receptive to traditional workshops at national conferences and on their own campuses.

In addition, there is a rapidly growing and easily understandable commitment to information literacy (by that or any other name), which for me can be defined as the set of skills and knowledge that enable someone to take better advantage of the full range of information resources that are multiplying in number, becoming more widely available, and offering more varied forms of information in support of almost any task imaginable [3]. Information literacy is usually conceived as something to be provided for undergraduates, but there is enormous anecdotal evidence that the faculty and professional staff at most colleges and universities are almost equally in need of increasing their own information literacy. This is yet another dimension of professional development needed by many. 
Meanwhile, many institutions report that while attendance at conventional professional development workshops is declining, faculty and others have become more receptive to more specific, explicit focused modular support formats, but participation still tends to be very limited. Many faculty who are compassionate pioneers, who demonstrate initiative in their own use of technology to improve teaching and learning and in their willingness to help colleagues make similar progress, are recognized and appreciated informally and inadequately supported. They are often overburdened and underrespected, subject to burnout and missing steps in promotion and tenure.

These individuals are a major underused resource at most colleges and universities. They can be supported and honored. Their skills and dedication can be exploited in the most positive sense, instead of advantage being taken of their good nature without compensation.

In summary, just when conventional resources and opportunities for professional development are dwindling and faculty receptivity to conventional forms of professional development is ebbing, we find that more people need more of it for keeping up in their own disciplines, for keeping up with new instructional options, and for keeping up with new kinds of information resources! Fortunately, but beginning only recently, we now have some tools and opportunities to provide new kinds of professional development that might enable more of our teachers and support personnel to make more effective educational uses of information technology. The new opportunities include taking advantage of some of the principles and strategies in the next section.

\section{PRINCIPLES, STRATEGIES, AND TOOLS}

One of the great strengths of higher education in the United States today is the rich variety of institutions, missions, structures, and approaches. In fact, few, if any, colleges are so homogeneous internally that any one approach, any one program is ever sufficient to improve teaching and learning. There is no one best way for doing or improving teaching and learning. There are many dimensions on which combinations can be formed.

The variety and number of different ways of combining faculty and students now ensures that a range of learning needs can be met. Here are some areas to consider when considering such restructuring:

\section{Structures (Space, Time)}

Link different configurations of groups and individuals synchronously and asynchronously; vary course meeting schedules. In higher education, it is the schedule, not space that is the final frontier.

\section{Media (Face-to-Face and Telecommunications)}

Combine voice with graphics, text, and other visual media.

Theory and Approaches (Pedagogy, Learning Theory, Cognitive Sciences, Instructional Design, and the Seven Principles of Good Practice in Undergraduate Education)

Develop and use eclectic amalgams of pedagogical theories and research. Be receptive to those principles that seem to span a variety of academic disciplines, as well as those that seem much more discipline specific. 


\section{Old and New (Old Categories and Goals, New Tools, New Opportunities, New Convergence)}

For decades, many teachers have known that some students learn better in different modalities and media than others; but very few faculty members had the necessary skills, time, support, and access to tools or media to respond to those different needs. New technology options permit meeting a variety of learning styles and needs in new ways, feasibly for the first time.

\section{A. The Principle of No Best Way: A Strategy of Organizing for Cumulative Success}

Choosing only one strategy for improving teaching and learning with technology doesn't work - never has and never will. Nor does it make sense to pursue too many goals and spread your institutional or individual effort too thin, even in the present environment of rapidly increasing opportunities, challenges, and complexity. Each college or university needs a process for carefully selecting, implementing, and modifying its own set of strategies.

On every campus, expectations continue to grow faster than available resources. The support service crisis gets worse as both institutions and individuals face too many attractive alternatives. No one alone has enough time and expertise to make the most of these choices. New applications of technology are making new forms of collaboration both essential and possible. It is time for collaborative change.

This approach offers a way of describing your current situation, analyzing your options, and developing a selective portfolio of strategies appropriate for your institution, division, or department. We recommend a balanced mixture of visionary thinking, realistic analysis, flexible planning, and pragmatic implementation - a Portfolio of Strategies for Collaborative Change that includes these six elements, each of which can be supported by a growing set of resources from The TLT Group in programs such as TLT Roundtables, Virtual TLT Centers, and so forth:

- Institutional Educational Mission (and Vision for improving teaching and learning with technology)

- Foundation (Minimum requirements for technology, support service infrastructure, and information literacy)

- Wide/Shallow Projects and Programs (Plan for annual initiatives or improvements, each of which benefits many faculty members and students well beyond a single course or department)

- Narrow/Deep Projects and Programs (Set of more focused, extensive, expensive, risky programs, each of which provides dramatic benefits but often for a relatively smaller fraction of the total institution)

- Culture of Collaboration and Learning (Developing a Nurturing Community in which colleagues help each other)

- Thoughtful Planning, Assessment, and Implementation (Tools and approaches that generate information to guide successful implementation, program revision, and realistic budgeting)

\section{B. The Principle of Keeping it Simple: A Strategy of Incremental Progress through Low-Threshold Applications and Activities (LTAs) [4]}

A new imperative for many colleges and universities is to engage almost all of the faculty in improving teaching and learning with information technology. For the last several years, most colleges and universities achieved a reasonable beginning and a balance in supporting their local pioneers or early adopters of instructional uses of information technology. The pioneers and the support professionals found ways of working together. But support professionals are neither numerous nor well prepared to 
enable the much larger numbers of mainstream faculty members and students to use technology in teaching and learning. Budgets available for this purpose are quite limited.

Recent experience suggests that this new, much larger cohort of mainstream faculty members is much more likely to be receptive to what they perceive as only modest changes that require them to reconceive only a little their identity, their roles, and their workload. They tend to resist the kinds of workshops and dislike the risks and quirks often associated with the most innovative educational uses of information technology. They rightfully resent implications that their work of past years or decades has been inadequate or incompetent. Many of them have much to offer and welcome opportunities to contribute to the overall change process - within reasonable limits.

A Low-Threshold Application (LTA) is a teaching-learning application of information technology that is reliable, accessible, easy to learn, non-intimidating, and incrementally inexpensive. Each LTA has observable positive consequences and contributes to important long-term changes in teaching and learning. "... the potential user (teacher or learner) perceives an LTA as not challenging, not intimidating, not requiring a lot of additional work or new thinking. LTAs... are also 'low-threshold' in the sense of having low incremental costs for purchase, training, support, and maintenance.”[5]

There are many kinds of thresholds. Some are more concrete: What technology is accessible to those involved? And some are more abstract: With which applications of technology are those involved really comfortable, confident? Whether a threshold is low or high depends on a variety of local conditions and personal attitudes. Hallowell [1] has suggested that fear is the greatest learning disability. Fear may be the greatest barrier to change, the highest threshold of all.

Every LTA is based on some technology that is either "almost ubiquitous," available commercially at low cost to teachers and learners, or available from open source-open course collections of instructional and professional development resources. The latter collections require little or no payment but encourage users to contribute to the development of the resources.

\section{The Principle of Learning from Each Other: A New and Simple Strategy of Professional Development That Exploits Unique Resources - Colleagues}

Professional development, almost by necessity, supports collegial learning. Indeed, some of the most powerful developmental experiences come not from highly paid professional speakers, but from the ranks of educators in one's own college. To facilitate such professional development, the following 10 guidelines are offered.

1. Hybrids always win. Just as hybrid courses are emerging as a dominant model in many undergraduate programs for sound reasons (combining the best of two worlds), hybrid professional development can be especially effective. Begin with and include occasional face-to-face elements and use online tools only recently available to support high-quality online interaction, learning, and so forth. Use and demonstrate recent insights from the cognitive sciences, as well as time-proven principles of pedagogy.

2. Build cohorts. Use and demonstrate techniques and tools to build community while improving teaching and learning; support ongoing interaction within a cohort within one institution or several institutions

3. Remember that deep learning and change take time. Engage and support participants for at least one 
academic year. [Note: We have not determined the minimum time that is adequate to complete a cycle of learning new approaches and tools, trying one, developing and using an assessment of that change, sharing information with cohort members, improving that change, helping at least one colleague outside the cohort to make a similar improvement and report progress and get feedback from cohort members. It may be that, ideally, the cycle would continue forever.]

4. An intensive face-to-face session is ideal as the beginning phase, both for building community and establishing the cohort as a mutually supportive group and for introducing a variety of useful options and eliciting the needs and goals of participants to help shape plans for later activities.

5. Introduce a variety of Low-Threshold Applications/Activities, varied by generic purpose, pedagogic role, technology used, and discipline specificity. Enable participants to find a few instructional resources that they can implement easily and rapidly in their own courses. Urge participants to pick easy targets for making their first change in one of their own courses.

6. Provide regular, frequent (at least monthly) opportunities for participants to report their intentions and initial results to their cohort colleagues and to get informal feedback from them.

7. Introduce assessment methodologies and principles adequate to enable participants to use an online assessment tool (e.g., Flashlight Online) to easily and rapidly develop and use a minimal online survey to collect feedback to guide further improvement of an instructional change.

8. Participants should be comfortable enough with each other within the cohort to establish a regular practice of reporting assessment results and ways in which the next use of the change that was being assessed will be altered and improved because of the data.

9. Help or mentor at least one colleague. Each participant is expected to and supported in helping a colleague outside the cohort to make a similar kind of change or improvement. Participants are urged once again to pick easy targets - people who are most likely to be receptive.

10. Introduce new colleagues to the process. Participants are encouraged to bring a new colleague, preferably one who is being helped to make a similar change, to one of the regular cohort events. These additional colleagues can become the core of another cohort. The process then becomes ongoing.

[Note: There might be the beginning of growth in regional conferences as part of a more viable approach to sustained professional development to meet new these new challenges (6).]

\section{TOOLS AND PRACTICES TO ENABLE PRINCIPLES AND STRATEGIES}

Of course, there are many new options for improving teaching and learning, but those that fit the following categories support doing so in ways likely to increase rather than undermine community, connectedness, and engagement among teachers, learners, and other academic professionals. 


\section{A. Personalizing Interaction}

Tools are rapidly emerging that enable faculty and students - or anyone else - to include their own voices easily and quickly within or attached to other media. The use of the human voice often adds a personal dimension and vitality to interactions well beyond plain text or visual images. Tools that enable this kind of personalization of synchronous and asynchronous interactions include RoboDemo and Elluminate, among others.

\section{B. Constructive Assessment (Feedback)}

The ability to create a survey on the web; make it available to respondents on the web; collect results on the web; analyze, display, and share results on the web makes it much easier, quicker, and more comfortable to seek and get data about teaching and learning. With some guidance, many can collect feedback in new ways that are much more likely to be used to improve practices and conditions for teaching and learning. One tool that enables this kind of constructive, rapid assessment is Flashlight Online.

\section{Collegial Sharing and Collaboration}

Many collections and repositories are now available. MERLOT, for example, goes well beyond merely assembling descriptions of instructional resources. MERLOT includes tools that encourage and enable users of the collection to provide peer reviews, to assemble personal lists of resources that can be shared, and to add new descriptions of instructional resources or related materials.

\section{Tools and Practices That Build and Support Collaboration}

Perhaps the most rapidly changing category is that of tools that enable groups to communicate at a distance synchronously in a variety of media. Many now permit one or more leaders or instructors to simultaneously reach a large group of people located anywhere in the world where they can each have access to the internet. The presenter can display slides, websites, and photographs. Participants can exchange text messages. Some systems permit every participant to speak and be heard by all the others. Some tools allow the leader to run a computer application and have all the participants see and hear exactly what the leader does. Some have a variety of mechanisms that permit the teacher to ask different kinds of questions that participants can respond to simultaneously, and the results can be aggregated and displayed for all to see almost immediately. Some examples include Elluminate and Communicast.

\section{CONCLUSION: SOME FINAL THOUGHTS ON BREAKING OLD AND NEW TABOOS}

To achieve the most within the framework described in this article, we need to break some old and some new taboos.

We need to acknowledge the need for information literacy programs for the faculty; moreover, we need to provide them.

We need to help people understand why and how the underlying real costs of higher education will continue to rise, and how unlikely it is that increasing use of information technology will significantly change that pattern. If you're really bold and politically naïve, point out how much this is like health care. 
We need to acknowledge the great variety of good teaching and good teachers. We need to challenge ourselves to support both the idiosyncratic and the mysterious, as well as those who more obviously reflect practices recommended by the most respected and sound approaches to improving education, such as the seven principles of good practice in undergraduate education, assessment and accountability standards, active learning, scholarship of teaching, and instructional design principles.

Finally, in professional development programs, we need to include everyone, including adjuncts, staff, and local community members. Indeed, if we are serious about engaging education, we need to move beyond learner-centered education to everyone-centered education!

\section{REFERENCES}

1. Hallowell, E. M., and Thompson, M. G. Finding the Heart of the Child: Essays on Children, Families, and Schools. Massachusetts: Association of Independent Schools in New England, Inc., 1993.

2. Moss, J. Personal Communication, 1993.

3. http://www.tltgroup.org/TailoredWebsites/InfoLit/BestPractices.htm

4. http://www.tltgroup.org/resources/rltas.html

5. http://www.tltgroup.org/LTAs/resources.htm

6. http://www.tltgroup.org/tltg-usfprofdevmodel.htm

For further info about TLT Group in general:

http://www.tltgroup.org

For information about the TLT Group's online and other events:

http://www.tltgroup.org/events.htm

For information on building community and connectedness online and on campus:

http://www.tltgroup.org/communityonlineoncampus.htm

For information about TLT Group's Information Literacy activities and links to ACRL's Information Literacy sites see:

http://www.tltgroup.org/TailoredWebsites/InfoLit/BestPractices.htm

For more information about Portfolio of Strategies

http://www.tltgroup.org/gilbert/strategiesbase.htm

For more information about Low-Threshold Applications/Activities LTAs

http://www.tltgroup.org/LTAs/Home.htm

LTA of the Week

http://tc.unl.edu/cansorge/lta/

\section{ACKNOWLEDGEMENTS}

I would like to acknowledge the hundreds of people that I have conversed and collaborated with. Foremost among them-my partners at TLT Group, Stephen C. Ehrmann and Sally S. Gilbert. Sally has read and suggested editorial changes to everything I write of any significance. Steve has challenged and strengthened every important idea. 


\section{ABOUT THE AUTHOR}

Steven W. Gilbert founded the Teaching, Learning, and Technology (TLT) Group, an independent nonprofit organization, originally affiliated with the American Association for Higher Education (AAHE), in January 1998. Previously he had been with the Teaching, Learning, and Technology Roundtable (TLTR) Program; he has he been with EDUCOM since 1983, serving as Vice President, and then came to AAHE as Director, Technology Projects, in July 1993 where he developed the TLT Roundtable concept and the AAHESGIT Listserv. He has helped 500 colleges and universities plan and organize for the improvement of teaching and learning through more effective use of information technology and resources.

At EDUCOM (now EDUCAUSE), Gilbert created and led the Educational Uses of Information Technology (EUIT) program and the EDUCOM Software Initiative (ESI) from 1985 through 1993. EUIT and ESI were volunteer programs involving over 3,000 campus and corporate officials, including over 800 voting participants. Gilbert also launched EDUCOM's Corporate Associates Program (1983-1993) to promote the active corporate participation and support of over 100 companies. Earlier (1984-1986), Gilbert developed and directed the EDUCOM Computer Literacy Project, surveying and facilitating the efforts of colleges and universities to help non-specialists use computers.

Before EDUCOM, Gilbert was a management consultant in philanthropy, advising corporations and foundations in the area of education and technology. His career began as a teacher and school administrator, including teaching mathematics and science at every level from K-12 at Princeton Day School, to teacher training in Princeton University's Teacher Preparation Program.

Gilbert's undergraduate degree in Mathematics was from Princeton University. He also earned an Ed. M. from the Harvard Graduate School of Education and an M.B.A. from the Wharton School of the University of Pennsylvania. 